\title{
Short communication: High-throughput sequencing approach to investigate Italian artisanal cheese production
}

\author{
Federica Biolcati, ${ }^{1,2 *}$ ○llario Ferrocino, ${ }^{2} \odot$ Maria Teresa Bottero, ${ }^{1} \odot$ and Alessandra Dalmasso ${ }^{1} \oplus$ \\ ${ }^{1}$ Dipartimento di Scienze Veterinarie, Università di Torino, 10095 Grugliasco, Italy \\ ${ }^{2}$ Dipartimento di Scienze Agrarie, Forestali e Alimentari (DISAFA), Università di Torino, 10095 Grugliasco, Italy
}

\begin{abstract}
In this study, high-throughput sequencing (HTS) was used to investigate the microbiota of Robiola di Roccaverano production, an artisanal Protected Designation of Origin soft cheese made with raw goat milk by addition of a natural milk starter (NMS), from the Piedmont region of Italy. Different steps of production of Robiola di Roccaverano cheese at one artisanal dairy were monitored. Matched samples of milk, NMS, curd, and 5-d and 15-d matured cheeses were collected at different periods of the year. The DNA sequences obtained by HTS belonged to 5 phyla: Proteobacteria, Firmicutes, Bacteroidetes, Actinobacteria, and Tenericutes. In milk, Proteobacteria and Firmicutes were mainly found, and several operational taxonomic units (OTU) belonging to contaminant bacteria such as Pseudomonas, Serratia, and Staphylococcus were observed. However, in NMS, curd, and 5- and 15-d cheeses, Firmicutes were principally observed where OTU of Lactococcus lactis were predominant, followed by Leuconostoc mesenteroides OTU. The results of the analysis showed high bacterial diversity in milk samples compared with NMS, curd, and 5- and 15-d cheeses, suggesting strong action of NMS in driving the characteristics of the final products. Key words: Robiola di Roccaverano, microbial characterization, high-throughput sequencing
\end{abstract}

\section{Short Communication}

Artisanal cheese manufacturing is receiving growing scientific interest, because these products preserve a typical indigenous microbiota that drives their final microbial characteristics. Several studies report that cheeses made with raw milk possess more intense flavors compared with others obtained from pasteurized milk, due to the activity of indigenous bacteria inhabiting the typical microbiota (Beuvier et al., 1997; Callon et

Received January 16, 2020.

Accepted June 15, 2020.

*Corresponding author: federica.biolcati@unito.it al., 2005; Montel et al., 2014). Robiola di Roccaverano is a soft and creamy artisanal cheese from the Piedmont region (Northwest Italy) that has received Protected Designation of Origin status. Technical policies establish that Robiola di Roccaverano is manufactured from at least $50 \%$ raw goat milk or by the addition of cow or sheep milk without the use of commercial starter. A natural milk starter (NMS) obtained by back slopping is used to start the fermentation process. In particular, milk from the evening milking session is left to ferment at room temperature and inoculated into fresh milk in the morning. After a few cycles, a stable starter culture is formed (Smid et al., 2014). On the first day of production, milk from 2 subsequent milking sessions (evening and morning) is inoculated with NMS and coagulated at room temperature with cow or goat rennet. The day after, the whey is drained to allow cheese formation. Roccaverano cheese may be consumed fresh, after $5 \mathrm{~d}$, or matured for approximately $15 \mathrm{~d}$ (Gazzetta Ufficiale della Repubblica Italiana, 2013).

It can therefore be assumed that the final microbiota of Robiola di Roccaverano cheese is highly influenced by the microbial composition of NMS as well as by the initial microbiota of raw milk employed during the cheese manufacturing process. Thus, it becomes interesting to monitor the microbiota dynamic through the production chain.

In the past, identification of microbial species was traditionally carried out using culture-dependent methods. However, these techniques were not reliable to characterize the entire food-associated microbiota; in fact, it is difficult to reproduce the optimal growing conditions in laboratory, and the species present in low number are outcompeted by others in high numbers (Stewart, 2012). Moreover, in recent decades, cultureindependent methodologies, based on direct analysis of DNA, have been used to characterize milk and dairy product microbiota (Quigley et al., 2013). Among these techniques, high-throughput sequencing (HTS) methods have been applied in recent years, allowing a rapid, sensitive, and deeper analysis of microbiota inhabiting the food matrices (Quigley et al., 2012; O'Sullivan et 
al., 2015; Alessandria et al., 2016; Soto del Rio et al., 2017).

The primary aim of this work was to monitor the microbiota dynamics during the cheese manufacturing process of an artisanal cheese factory of Robiola di Roccaverano cheese following each production step (milk, NMS, curd, and 5-d and 15-d cheeses), using an HTS approach. To achieve this purpose, one artisanal Roccaverano facility was followed for $1 \mathrm{yr}$, and samples were collected in triplicate in each season (spring, summer, autumn, winter). On the first day of sampling, NMS, milk, and curd were collected, and 5 and $15 \mathrm{~d}$ after the beginning of production, cheese samples from the same batch were collected. In total, 60 samples of NMS (n $=12)$, milk $(\mathrm{n}=12)$, curd $(\mathrm{n}=12)$, cheeses after $5 \mathrm{~d}$ of ripening $(\mathrm{n}=12)$, and cheeses after $15 \mathrm{~d}$ of ripening $(\mathrm{n}=12)$ were aseptically collected and transported to the laboratory at $4^{\circ} \mathrm{C}$. Samples were stored at $-20^{\circ} \mathrm{C}$ before DNA extraction. Cheese samples were analyzed with no distinction between core or surface, due to the soft texture of Robiola di Roccaverano.

Nucleic acid extraction from milk and NMS samples was performed in each sample in triplicate $(3 \mathrm{~mL}$ total). Each technical replicate $(1 \mathrm{~mL})$ was centrifuged in cooled condition at $12,000 \times g$ for $30 \mathrm{~min}$, and the surfactant was removed with sterile cotton. The pellet was washed in $500 \mu \mathrm{L}$ of PBS and resuspended in 200 $\mu \mathrm{L}$ of ATL buffer and proteinase $\mathrm{K}$ and extracted using a DNeasy Blood and Tissue Kit (Qiagen, Hilden, Germany) following the manufacturer's instructions. Curd and cheese samples were extracted from each sample in triplicate using the Dneasy Blood and Tissue Kit with some modifications as reported by Dalmasso et al. (2016). Briefly $400 \mathrm{mg}$ of each technical replicate were mixed and eluted in $50 \mathrm{~mL}$ of elution buffer from the kit. The quality and purity of the DNA extracted was assessed by the Nanodrop 2000 (Thermo Fisher Scientific, Waltham, MA), and the concentration was assessed using the QUBIT dsDNA HS Assay Kit (Thermo Fisher Scientific). DNA extracted from the 3 technical replicates were standardized at $5 \mathrm{ng} / \mu \mathrm{L}$ and pooled before the PCR step.

The V3-V4 region of the 16S rRNA gene was targeted using primers and procedures described by Klindworth et al. (2013). An Agencourt AMPure Kit (Beckman Coulter, Milan, Italy) was used to purify PCR amplicons, and the resulting products were tagged using the Nextera XT Index Kit (Illumina Inc., San Diego, CA) according to the manufacturer's instructions. The sequencing reactions were conducted with a MiSeq System (Illumina Inc.) with V3 chemistry, according to manufacturer instructions, generating $250 \mathrm{bp}$ pairedend reads.
After sequencing, reads were first assembled using FLASH software (Magoč and Salzberg, 2011) with default parameters. Subsequently the jointed reads were quality filtered using QIIME 1.9.0 software (Caporaso et al., 2011). Chimera filtering was conducted using USEARCH v. 8.1 software (Edgar et al., 2011) with a $16 \mathrm{~S}$ reference database v. 9 [Ribosomal Database Project (RDP) classifier training database; Wang et al., 2007]. Selection of operational taxonomic units (OTU) was performed at $99 \%$ similarity using UCLUST clustering methods (Edgar, 2010), and the centroid sequence of each cluster was used to assign taxonomy using Greengenes $16 \mathrm{~S}$ rRNA gene database v. 13.8 (McDonald et al., 2012) by means of the RDP classifier (Wang et al., 2007). $\alpha$-Diversity was calculated through the diversity function of the VEGAN package of R (www.r-project .org; Dixon, 2003). Weighted UniFrac distance matrices obtained through QIIME (Caporaso et al., 2011) were imported into $\mathrm{R}$ to obtain principal coordinate analysis plots.

A filtered OTU table was generated at $0.5 \%$ abundance in at least 2 samples through QIIME (Supplemental Table S1, https://doi.org/10.3168/jds.2020 -18208). The relative abundances of OTU from each matrix were averaged (Figure 1A). The OTU table displays the highest taxonomy resolution that was reached by the $16 \mathrm{~S}$ rRNA gene data analyzed; when the taxonomy assignment was not able to reach species level, the genus or family name were displayed (Supplemental Table S1).

Sequencing data were deposited in the Sequence Read Archive of the National Center for Biotechnology Information (NCBI; https://www.ncbi.nlm.nih.gov/) under Bioproject accession number PRJNA626588. Poor DNA quality excluded 2 milk samples (L29 from summer and L55 from autumn).

A total of 7,101,439 raw sequences $(2 \times 250 \mathrm{bp})$ were obtained from the sequencing; after filtering, 5,945,462 high-quality $16 \mathrm{~S}$ rRNA gene sequences with a sequence length of $476 \mathrm{bp}$ and an average of 102,508 reads per sample were recovered. The number of reads for each matrix were 1,393,967 for NMS samples, 551,691 for milk samples, 977,681 for curd, 1,434,279 for 5-d cheese, and $1,587,844$ for 15 -d cheese. The rarefaction analysis and estimated samples coverage indicated adequate coverage for all samples (estimated sample coverage higher than $96 \%$ for all the samples; Figure 2).

The taxonomic assignment of the sequences obtained belonged to 5 phyla: Proteobacteria, Firmicutes, Bacteroidetes, Actinobacteria, and Tenericutes. Among these, milk samples were particularly rich in Proteobacteria and Firmicutes, whereas in NMS, curd, and 5-d and 15-d cheeses, Firmicutes were mainly observed (Supple- 

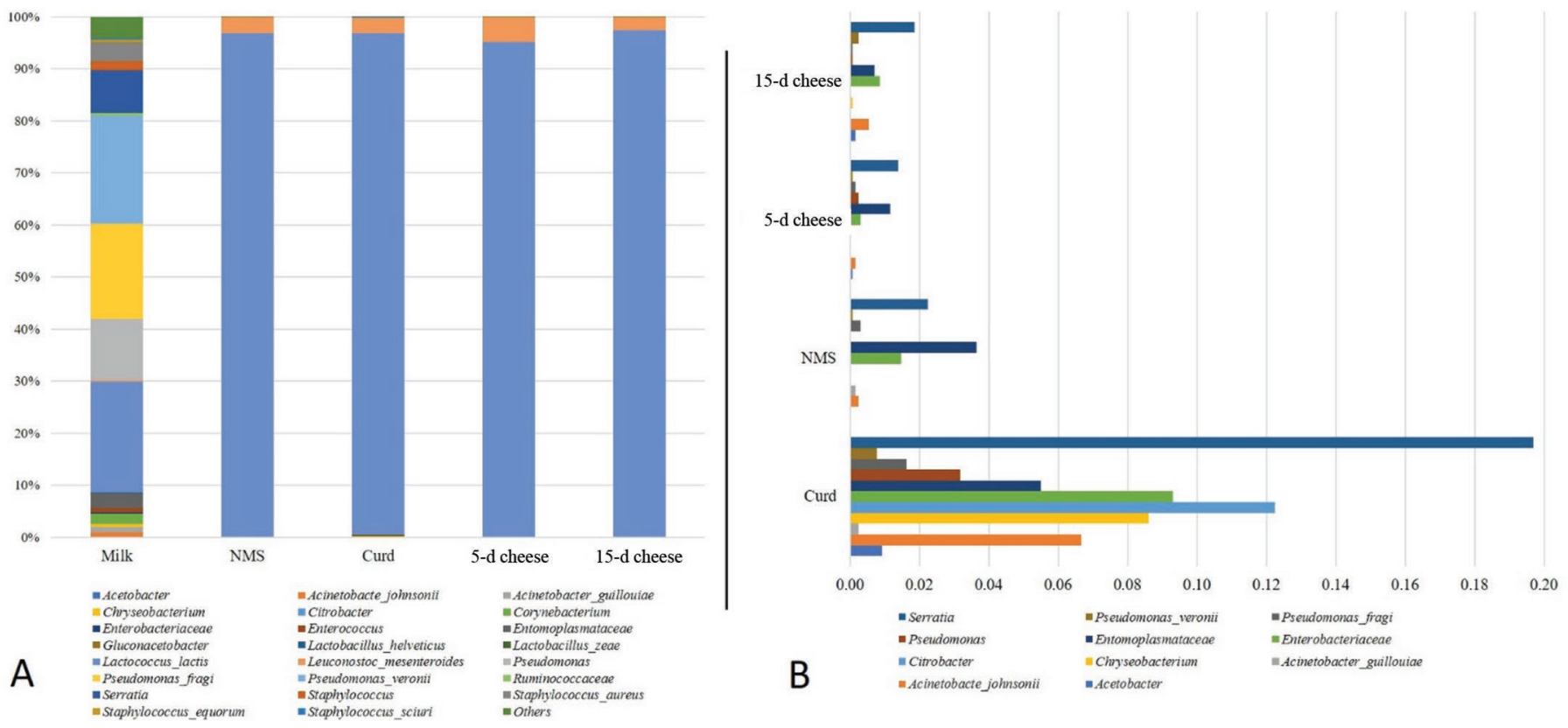

Figure 1. (A) Relative abundance (\%) of the taxa detected with $16 \mathrm{~S}$ sequencing. Only operational taxonomic units (OTU) with an incidence above $0.5 \%$ in at least 2 samples are shown. The OTU abundances from milk, natural milk starter (NMS), curd, and 5-d and 15-d ripened cheese samples were averaged. (B) Subdominant populations of NMS, curd, and 5-d and 15-d cheeses.

mental Table S1, https://doi.org/10.3168/jds.2020 -18208). These results agreed with those described in raw milk by Quigley et al. (2012) and in traditional Plaisentif and Liqvan cheeses (Dalmasso et al., 2016; Ramezani et al., 2017). In particular, 23 OTU were identified: 12 OTU at genus level and 11 OTU at species level (Supplemental Table S1). A total of 9 genera of gram-negative bacteria (Pseudomonas, Serratia, Corynebacterium, Chryseobacterium, Citrobacter, Acinetobacter, Gluconacetobacter, and Entomoplasmataceae) and 4 genera of gram-positive bacteria (Staphylococcus, Ruminococcus, Lactobacillus, and Lactococcus) were found. Furthermore, among these genera, 9 species were discriminated: Lactococcus lactis, Leuconostoc mesenteroides, Lactobacillus helveticus, Lactobacillus zeae, Pseudomonas veronii, Pseudomonas fragi, Staphylococcus aureus, Staphylococcus equorum, and Staphylococcus sciuri (Supplemental Table S1).

$\alpha$-Diversity indices (Shannon and Chao1 index) as well as the number of observed species (Figure 2) showed that raw milk samples had generally a higher level of complexity compared with the other matrices. Generally, even if it was not possible to identify some common OTU among all milk samples, the most encountered genera were Pseudomonas and Lactococcus. Pseudomonas spp. were found with a relative abundance between 30 and $80 \%$ in 8 out of 10 samples. Other OTU belonging to psychrotrophic taxa such as Acinetobacter, Chryseobacterium, Corynebacterium, and Serratia were identified (Supplemental Figure S1, Table S1, https://doi.org/10.3168/jds.2020-18208). Serratia OTU were found with a high relative abundance in 2 milk samples (between 14 and 29\%; Supplemental Table S1, Figure S1, https://doi.org/10.3168/ jds.2020-18208). The presence of this psychrotolerant genus in milk is not unexpected and could be related to the ability of microorganisms of this genera to grow at the cold temperatures used for the storage of raw materials (Quigley et al., 2013). Several studies have reported that, among the numerous psychrotrophic bacteria isolated from milk, Pseudomonas is dominant in raw milk microbiota (Eneroth et al., 2000; Ercolini et al., 2009). Members of this genus are normally present in water, and they might derive from the water used to rinse the milking machinery. Genera such as Pseudomonas, Acinetobacter, and Chryseobacterium are known as environmental microbial sources of contamination, and some of them could be responsible for milk spoilage due to the activity of proteolytic and lipolytic enzymes (Hantsis-Zacharov et al., 2008; Ercolini et al., 2009; Montel et al., 2014).

Among undesirable bacteria, several OTU belonging to the genus Staphylococcus were detected in 6 out 10 milk samples, with a relative abundance $>1 \%$. Additionally, in 5 out 10 samples, the presence of $S$. aureus was reported, with a relative abundance $>2 \%$, and 1 sample showed high relative abundance $(>19 \%)$. Other staphylococcal species, such as the coagulase-negative 

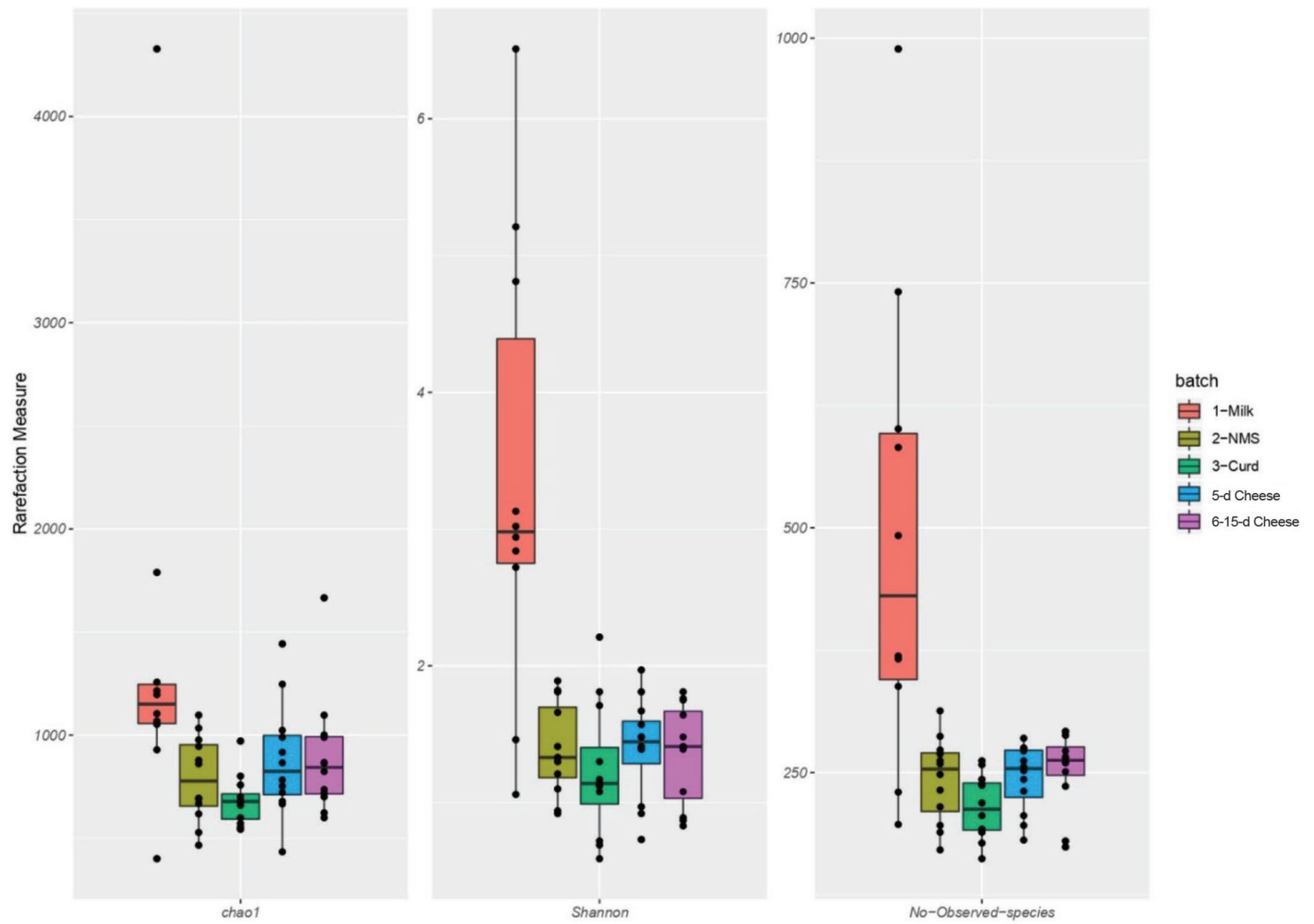

Figure 2. Boxplots describing $\alpha$-diversity measures of milk, natural milk starter (NMS), curd, and 5-d and 15-d ripened cheese. Boxes represent the interquartile range (IQR) between the first and third quartiles, and the line inside represents the median value. Whiskers denote the lowest and the highest values within $1.5 \times \mathrm{IQR}$, respectively, and circles represent outliers beyond the whiskers.

S. equorum and S. sciuri were also identified (Supplemental Table S1, Figure S1). Several OTU belonging to the Enterobacteriaceae family were also found in 8 out 10 milk samples, with a relative abundance range from 0.02 to $0.94 \%$. These microorganisms are defined as an indicator of hygiene and quality of production. The presence of staphylococci in goat milk has already been described, and, together with Pseudomonas spp., lactic acid bacteria (LAB), and Enterobacteriaceae, staphylococci have been defined as the predominant bacterial groups in milk from different sources (Quigley et al., 2011; McInnis et al., 2015).

Among LAB, other than Lc. lactis, which was found with a relative abundance higher than $26 \%$ in 3 out of 10 of milk samples, also Leuc. mesenteroides, Lb. helveticus, Lb. zeae, and Enterococcus spp. were detected in low numbers (Supplemental Figure S1, Table S1). These species are defined as non-starter LAB because they are mainly involved in the ripening process, through the fermentation of residual lactose or other sugars and citrate, peptide, and amino acid production, involved in formation of aromatic compounds (Marino et al., 2019).

Milk samples also harbored few OTU of acetic acid bacteria, such as Gluconacetobacter and Acetobacter, as subdominant genera (Supplemental Table S1, Figure S1). Their presence has been previously reported in cow milk, and they have been frequently isolated or identified in the metagenome of natural fermented foods such as kefir and kombucha (Nguyen et al., 2008; Gao et al., 2013; Marino et al., 2019). They also have a pivotal role during cocoa bean fermentation (Mota-Gutierrez et al., 2018).

Unusually, the family Entomoplasmataceae was found with $24 \%$ relative abundance in 1 milk sample (Supplemental Table S1, Figure S1, https://doi.org/10.3168/ 
jds.2020-18208). Previous studies reported the presence of this family in cow milk and in the microbiome of ants (Song et al., 2017; Chua et al., 2018), and it could be considered an environmental source of contamination.

The milk matrix showed high variability compared with the other matrices; in fact, principal coordinate analysis with a weighted UniFrac distance matrix, as well as the Adonis and Anosim statistical tests (Figure 3A), clearly group together samples of NMS, curd, and cheese, underlining the low microbial variability of these samples. In fact, these samples always showed similar qualitative and quantitative microbial compositions, characterized by the same relative abundance of species (Figure 1A). They were united by the dominance of OTU belonging to LAB species, principally Lc. lactis, with a relative abundance from 87 to $100 \%$ in NMS, 66 to $100 \%$ in curd, 70 to $100 \%$ in 5-d cheese, and 93 to $100 \%$ in 15-d cheese, relative to the total reads (Supplemental Figure S1, Table S1). Leuconostoc mesenteroides was also found in minor proportions, with a relative abundance from 0.01 to $12 \%$ in NMS, 0 to $34 \%$ in curd, 0 to $30 \%$ in fresh cheese, and 0 to $4 \%$ in 15 -d cheese, of the total reads. Other OTU of LAB belonging to Enterococcus spp. were found in low proportions in NMS, curd, and cheese; however, aside from milk samples, OTU of $L b$. zeae were present only in 15-d matured cheese. Finally, Lb. helveticus OTU were observed in all samples except for NMS (Supplemental Table S1; Figure 1A). The microbiota of the undefined starter cultures used for production of other cheese varieties have already been studied, underlining the high prevalence of Lc. lactis species, followed by a small community of Leuc. mesenteroides (Erkus et al., 2013). The great abundance of Lc. lactis in NMS samples could be explained by the fact that production of NMS takes place via natural fermentation of milk at room temperature, which causes the increment of mesophilic lactic flora, particularly lactococci (Wouters et al., 2002). On the other hand, Leuconostoc, found in low proportion in NMS, has a poor starter function but is involved in cheese maturation through the production of aromatic compounds such as acethaldeydes, dyacetl, and acetoin (McSweeney and Sousa, 2000).

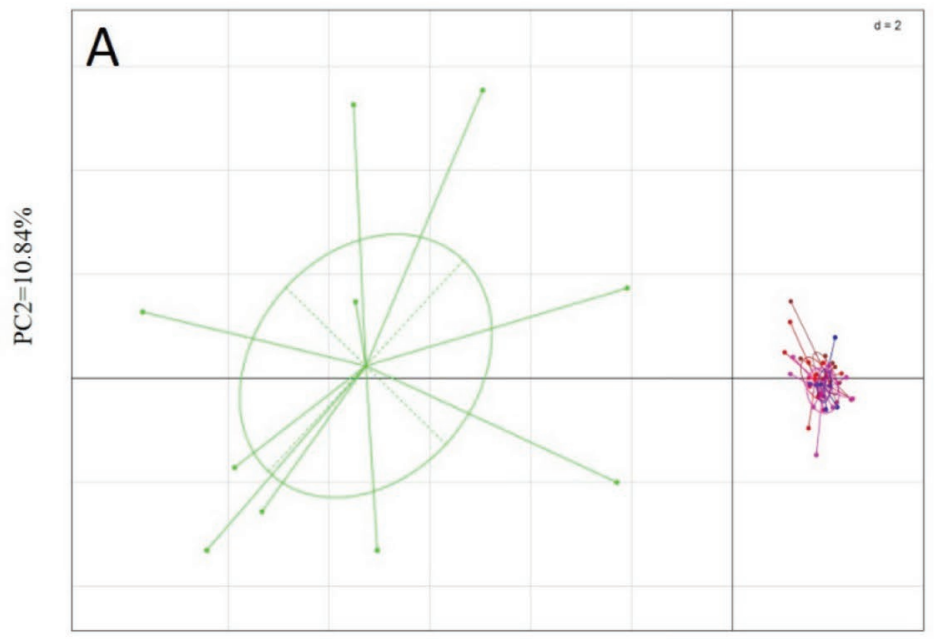

$\mathrm{PCl}=59.91 \%$

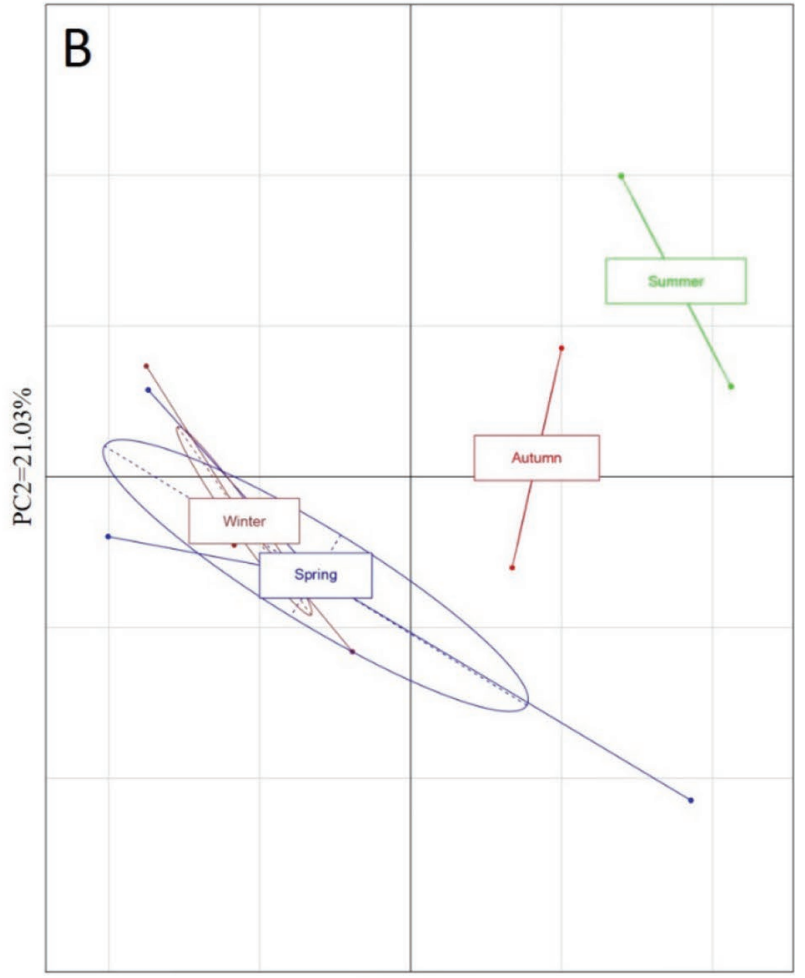

$\mathrm{PCl}=38.27 \%$

Figure 3. (A) Principal component (PC) analysis based on operational taxonomic unit (OTU) relative abundance of milk (green), natural milk starter (NMS, brown), curd (red), 5-d ripened cheese (blue), and 15-d ripened cheeses (magenta). The first component (horizontal) accounts for $59.91 \%$ of variance, and the second component (vertical) accounts for $10.84 \%$. (B) PC analysis based on OTU relative abundance of milk samples collected in different seasons. The first component (horizontal) accounts for $38.27 \%$ of variance, and the second (vertical) component for $21.03 \%$. 
Microbial characterization of Robiola di Roccaverano production has been performed in previous studies through culture-dependent analysis investigating LAB populations (Biolcati et al., 2019, 2020). These studies highlighted the elevated number of LAB in NMS and cheese, in which Lc. lactis and Leuc. mesenteroides were the prevalent species identified by means of random amplified polymorphic DNA (RAPD)-PCR, confirming what has been found through the HTS approach.

The microbial dynamics of the facility during the production of Roccaverano cheese has been observed, and, despite the great influence of NMS, several OTU found in milk samples with elevated relative abundance were present as subdominant populations during the production steps (Figure 1B). We further observed OTU of psychrotrophic bacteria such as Acinetobacter, Chriseobacterium, Pseudomonas, and Serratia, but also Enterobacteriaceae, Citrobacter, and Entomoplasmataceae, in NMS, curd, and 5- and 15-d cheese samples. A higher relative abundance was observed in the early steps of production, such as curd, where the addition of the NMS was quite recent. Afterword, reduction of their relative abundance was observed over the later production steps (Figure 1B). This finding strengthens the hypothesis that the core microbial population of the NMS had a strong influence on the microbiota of the final product, where the high variability assessed in milk samples was lost.

The homogenization of microbial population in the final product, compared with the initial steps of production, has already been observed in cheese obtained from milk of different origins (Alessandria et al., 2016; Dalmasso et al., 2016; Ramezani et al., 2017). Although no analysis has been performed, it could also be supposed that the addition of NMS had a function in prevention of the growth and spreading of contaminant bacteria, as previously suggested by Alessandria et al. (2016).

Finally, we decided to follow the seasonality of this artisanal cheese production to detect any possible microbiota differences in samples from the same period and among different seasons. As suggested by principal component analysis reported in Figure 3A, samples of NMS, curd, and 5- and 15-d cheeses clustered together, showing no seasonal differences. Among milk samples, despite the low number of seasonal differences observed in summer and autumn, winter and spring were grouped together (Figure 3B). The microbial composition of raw milk could be influenced by microbial sources directly in contact with raw milk (teat surface, milking machine, and tank) and indirectly from the microbiota occurring in dairy equipment, air, dust, drinking and washing water, feed, stable conditions, and dairy environment (Quigley et al., 2013; Montel et al., 2014).
With the advent of HTS technology, the methodology used to analyze the microbiota associated with food matrices has changed. In this study, HTS permitted characterization of the microbiota involved in Robiola di Roccaverano cheese production as culture-independent techniques alternative to traditional analysis. It also provided several snapshots of the intermediate steps during cheese production, enabling tracking of the progression of bacterial communities from raw milk to the final ripened cheese, and illustrating the importance of NMS in the final product characteristics. The results suggest that despite the traditional cheese manufacturing practices, the location of the dairy in a rural area, and the raw materials used for the production process, the cheese maker is able to standardize this artisanal production.

\section{ACKNOWLEDGMENTS}

This work was supported by the University of Turin, Grugliasco (TO), Italy (ex 60\% grant). The authors declare no conflict of interest.

\section{REFERENCES}

Alessandria, V., I. Ferrocino, F. De Filippis, M. Fontana, K. Rantsiou, D. Ercolini, and L. Cocolin. 2016. Microbiota of an Italian Granalike cheese during manufacture and ripening, unraveled by $16 \mathrm{~S}$ rRNA-based approaches. Appl. Environ. Microbiol. 82:3988-3995. https://doi.org/10.1128/AEM.00999-16.

Beuvier, E., K. Berthaud, S. Cegarra, A. Dasen, S. Pochet, S. Buchin, and G. Duboz. 1997. Ripening and quality of Swiss-type cheese made from raw, pasteurized or microfiltered milk. Int. Dairy J. 7:311-323. https://doi.org/10.1016/S0958-6946(97)00015-0.

Biolcati, F., M. T. Bottero, and A. Dalmasso. 2019. Microbiological analysis of the Robiola di Roccaverano cheese by means of traditional culturing methods. Ital. J. Food Saf. 8:209-212. https://doi .org/10.4081/ijfs.2019.8574.

Biolcati, F., C. Andrighetto, M. T. Bottero, and A. Dalmasso. 2020. Microbial characterization of an artisanal production of Robiola di Roccaverano cheese. J. Dairy Sci. 103:4056-4067. https://doi.org/ 10.3168/jds.2019-17451.

Callon, C., J. L. Berdagué, E. Dufour, and M. C. Montel. 2005. The effect of raw milk microbial flora on the sensory characteristics of Salers-type cheeses. J. Dairy Sci. 88:3840-3850. https://doi.org/10 .3168/jds.S0022-0302(05)73069-1.

Caporaso, J. G., J. Kuczynski, J. Stombaugh, K. Bittinger, F. D. Bushman, E. K. Costello, N. Fierer, A. G. Peña, J. K. Goodrich, J. I. Gordon, G. A. Huttley, S. T. Kelley, D. Knights, J. E. Koenig, R. E. Ley, C. A. Lozupone, D. McDonald, B. D. Muegge, M. Pirrung, J. Reeder, J. R. Sevinsky, P. J. Turnbaugh, W. A. Walters, J. Widmann, T. Yatsunenko, J. Zaneveld, and R. Knight. 2011. QIIME allows analysis of high-throughput community sequencing data. Nat. Methods 7:335-336. https://doi.org/10.1038/nmeth.f .303.QIIME

Chua, K., S. Song, H. Yong, W. See-Too, W. Yin, and K. Chan. 2018. Microbial community composition reveals spatial variation and distinctive core microbiome of the weaver ant Oecophylla smaragdina in Malaysia. Sci. Rep. 8:10777. https://doi.org/10.1038/ s41598-018-29159-2.

Dalmasso, A., M. Soto del Rio, T. Civera, D. Pattono, B. Cardazzo, and M. T. Bottero. 2016. Characterization of microbiota in 
Plaisentif cheese by high-throughput sequencing. Lebensm. Wiss. Technol. 69:490-496. https://doi.org/10.1016/j.lwt.2016.02.004.

Dixon, P. 2003. VEGAN, a package of R functions for community ecology. J. Veg. Sci. 14:927-930. https://doi.org/10.1111/j.1654-1103 .2003.tb02228.x.

Edgar, R. C. 2010. Search and clustering orders of magnitude faster than BLAST. Bioinformatics 26:2460-2461. https://doi.org/10 .1093 /bioinformatics/btq461.

Edgar, R. C., B. J. Haas, J. C. Clemente, C. Quince, and R. Knight. 2011. UCHIME improves sensitivity and speed of chimera detection. Bioinformatics 27:2194-2200. https://doi.org/10.1093/ bioinformatics/btr381.

Eneroth, A., S. Ahrné, and G. Molin. 2000. Contamination routes of Gram-negative spoilage bacteria in the production of pasteurised milk, evaluated by randomly amplified polymorphic DNA (RAPD). Int. Dairy J. 10:325-331. https://doi.org/10.1016/S0958 $-6946(00) 00055-8$.

Ercolini, D., F. Russo, I. Ferrocino, and F. Villani. 2009. Molecular identification of mesophilic and psychrotrophic bacteria from raw cow's milk. Food Microbiol. 26:228-231. https://doi.org/10.1016/ j.fm.2008.09.005.

Erkus, O., V. C. L. de Jager, M. Spus, I. J. van Alen-boerrigter, I. M. H. van Rijswijck, L. Hazelwood, P. W. M. Janssen, S. A. F. T. van Hijum, M. Kleerebezem, and E. J. Smid. 2013. Multifactorial diversity sustains microbial community stability. ISME J. 7:2126-2136. https://doi.org/10.1038/ismej.2013.108.

Gao, J., F. Gu, J. He, J. Xiao, Q. Chen, H. Ruan, and G. He. 2013. Metagenome analysis of bacterial diversity in Tibetan kefir grains. Eur. Food Res. Technol. 236:549-556. https://doi.org/10.1007/ s00217-013-1912-2.

Gazzetta Ufficiale della Repubblica Italiana. 2013. Anno 154, numero 160, 52-54. Accessed Dec. 15, 2019. https://www.gazzettaufficiale .it/eli/gu/2013/07/10/160/sg/pdf.

Hantsis-Zacharov, E., T. Shakéd, Y. Senderovich, and M. Halpern. 2008. Chryseobacterium oranimense sp. nov., a psychrotolerant, proteolytic and lipolytic bacterium isolated from raw cow's milk. Int. J. Syst. Evol. Microbiol. 58:2635-2639. https://doi.org/10 .1099 /ijs.0.65819-0.

Klindworth, A., E. Pruesse, T. Schweer, J. Peplies, C. Quast, M. Horn, and F. O. Glöckner. 2013. Evaluation of general $16 \mathrm{~S}$ ribosomal RNA gene PCR primers for classical and next-generation sequencing-based diversity studies. Nucleic Acids Res. 41:e1-e11. https:// doi.org/10.1093/nar/gks808.

Magoč, T., and S. L. Salzberg. 2011. FLASH: Fast length adjustment of short reads to improve genome assemblies. Bioinformatics 27:2957-2963. https://doi.org/10.1093/bioinformatics/btr507.

Marino, M., G. Dubsky de Wittenau, E. Saccà, F. Cattonaro, A. Spadotto, N. Innocente, S. Radovic, E. Piasentier, and F. Marroni. 2019. Metagenomic profiles of different types of Italian high-moisture Mozzarella cheese. Food Microbiol. 79:123-131. https://doi .org/10.1016/j.fm.2018.12.007.

McDonald, D., M. N. Price, J. Goodrich, E. P. Nawrocki, T. Z. DeSantis, A. Probst, G. L. Andersen, R. Knight, and P. Hugenholtz. 2012. An improved Greengenes taxonomy with explicit ranks for ecological and evolutionary analyses of bacteria and archaea. ISME J. 6:610-618. https://doi.org/10.1038 /ismej.2011.139.

McInnis, E. A., K. M. Kalanetra, D. A. Mills, and E. A. Maga. 2015. Analysis of raw goat milk microbiota: Impact of stage of lactation and lysozyme on microbial diversity. Food Microbiol. 46:121-131. https://doi.org/10.1016/j.fm.2014.07.021.

McSweeney, P. L. H., and M. J. Sousa. 2000. Biochemical pathways for the production of flavour compounds in cheeses during ripening: A review. Lait 80:293-324. https://doi.org/10.1051/lait:2000127.

Montel, M.-C., S. Buchin, A. Mallet, C. Delbes-Paus, D. A. Vuitton, N. Desmasures, and F. Berthier. 2014. Traditional cheeses: Rich and diverse microbiota with associated benefits. Int. J. Food Mi- crobiol. 177:136-154. https://doi.org/10.1016/j.ijfoodmicro.2014 .02 .019 .

Mota-Gutierrez, J., C. Botta, I. Ferrocino, M. Giordano, M. Bertolino, P. Dolci, M. Cannoni, and L. Cocolin. 2018. Dynamics and biodiversity of bacterial and yeast communities during fermentation of cocoa beans. Appl. Environ. Microbiol. 84:e01164-18. https://doi .org/10.1128/AEM.01164-18.

Nguyen, V. T., B. Flanagan, M. J. Gidley, and Æ. G. A. Dykes. 2008. Characterization of cellulose production by a Gluconacetobacter xylinus strain from kombucha. Curr. Microbiol. 57:449-453. https: //doi.org/10.1007/s00284-008-9228-3.

O'Sullivan, D.J., P.D. Cotter, O. O'Sullivan, L. Giblin, P.L.H. Mcsweeney, and J. Sheehan., 2015. Temporal and spatial differences in microbial composition during the manufacture of a continentaltype cheese. Appl. Environ. Microbiol. 81:2525-2533. https://doi .org/10.1128/AEM.04054-14

Quigley, L., O. O'Sullivan, T. P. Beresford, R. P. Ross, G. F. Fitzgerald, and P. D. Cotter. 2011. Molecular approaches to analysing the microbial composition of raw milk and raw milk cheese. Int. J. Food Microbiol. 150:81-94. https://doi.org/10.1016/j.ijfoodmicro .2011.08.001.

Quigley, L., O. O'Sullivan, T. P. Beresford, R. P. Ross, G. F. Fitzgerald, and P. D. Cotter. 2012. High-throughput sequencing for detection of subpopulations of bacteria not previously associated with artisanal cheeses. Appl. Environ. Microbiol. 78:5717-5723. https:/ /doi.org/10.1128/AEM.00918-12.

Quigley, L., O. O'Sullivan, C. Stanton, T. P. Beresford, R. P. Ross, G. F. Fitzgerald, and P. D. Cotter. 2013. The complex microbiota of raw milk. FEMS Microbiol. Rev. 37:664-698. https://doi.org/10 .1111/1574-6976.12030.

Ramezani, M., S. M. Hosseini, I. Ferrocino, M. A. Amoozegar, and L. Cocolin. 2017. Molecular investigation of bacterial communities during the manufacturing and ripening of semi-hard Iranian Liqvan cheese. Food Microbiol. 66:64-71. https://doi.org/10.1016/ j.fm.2017.03.019.

Smid, E. J., O. Erkus, M. Spus, J. C. Wolkers-Rooijackers, S. Alexeeva, and M. Kleerebezem. 2014. Functional implications of the microbial community structure of undefined mesophilic starter cultures. Microb. Cell Fact. 13(Suppl. 1):S2. https://doi.org/10.1186/ 1475-2859-13-S1-S2.

Song, Y., Y. Huang, G. Hu, X. Guo, H. C. Z. Cao, T. Wang, H. Lin, F. Yang, and P. Liu. 2017. Microbial diversity in milk from Holstein dairy cattle with mastitis in southern China using Illumina MiSeqbased analysis. Pak. Vet. J. 37:129-134.

Soto del Rio, M., A. Dalmasso, T. Civera, and M. T. Bottero. 2017. Characterization of bacterial communities of donkey milk by highthroughput sequencing. Int. J. Food Microbiol. 251:67-72. https:/ /doi.org/10.1016/j.ijfoodmicro.2017.03.023.

Stewart, E. J. 2012. Growing unculturable bacteria. J. Bacteriol. 194:4151-4160. https://doi.org/10.1128/JB.00345-12.

Wang, Q., G. M. Garrity, J. M. Tiedje, and J. R. Cole. 2007. Naïve Bayesian classifier for rapid assignment of rRNA sequences into the new bacterial taxonomy. Appl. Environ. Microbiol. 73:52615267. https://doi.org/10.1128/AEM.00062-07.

Wouters, J. T. M., E. H. E. Ayad, J. Hugenholtz, and G. Smit. 2002. Microbes from raw milk for fermented dairy products. Int. Dairy J. 12:91-109. https://doi.org/10.1016/S0958-6946(01)00151-0.

\section{ORCIDS}

Federica Biolcati $\odot$ https://orcid.org/0000-0002-0797-7178 Ilario Ferrocino @ https://orcid.org/0000-0002-1657-0054 Maria Teresa Bottero (ํ) https://orcid.org/0000-0002-0803-9730 Alessandra Dalmasso 누 https://orcid.org/0000-0002-9991-9046 